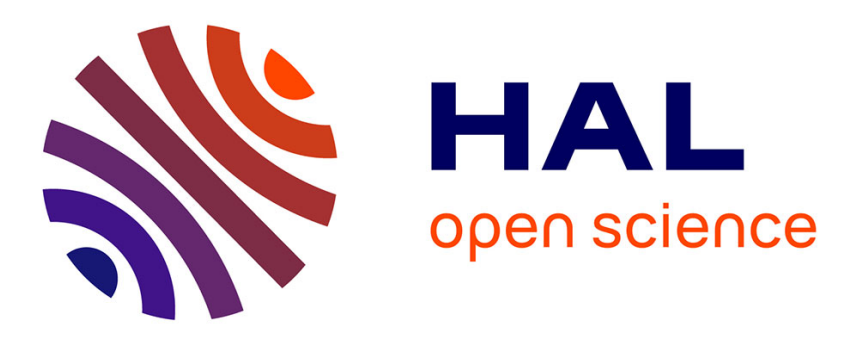

\title{
Spatial variation of negative ion density in a volume $\mathrm{H}-$ ion source
}

P. Devynck, M. Bacal, J. Bruneteau, F. Hillion

\section{To cite this version:}

P. Devynck, M. Bacal, J. Bruneteau, F. Hillion. Spatial variation of negative ion density in a volume H- ion source. Revue de Physique Appliquée, 1987, 22 (8), pp.753-759. 10.1051/rphysap:01987002208075300 . jpa-00245605

\section{HAL Id: jpa-00245605 https://hal.science/jpa-00245605}

Submitted on 1 Jan 1987

HAL is a multi-disciplinary open access archive for the deposit and dissemination of scientific research documents, whether they are published or not. The documents may come from teaching and research institutions in France or abroad, or from public or private research centers.
L'archive ouverte pluridisciplinaire HAL, est destinée au dépôt et à la diffusion de documents scientifiques de niveau recherche, publiés ou non, émanant des établissements d'enseignement et de recherche français ou étrangers, des laboratoires publics ou privés. 
Classification

Physics Abstracts

$29.25 \mathrm{C}-52.25 \mathrm{~L}-52.50 \mathrm{D}$

\title{
Spatial variation of negative ion density in a volume $\mathbf{H}^{-}$ion source
}

\author{
P. Devynck, M. Bacal, J. Bruneteau and F. Hillion \\ Laboratoire de Physique des Milieux Ionisés, Laboratoire du C.N.R.S., Ecole Polytechnique, 91128 \\ Palaiseau, France
}

(Reçu le 8 janvier 1987, révisé le 3 mars 1987, accepté le 28 avril 1987)

\begin{abstract}
Résumé. - Le profil de densité des ions $\mathrm{H}^{-}$est mesuré le long de l'axe d'une source multipolaire hybride d'ions $\mathrm{H}^{-}$, pour différentes pressions, en utilisant la technique de photodétachement. On trouve que dans une région proche de l'électrode plasma (première électrode de l'extracteur), la densité d'ions $\mathrm{H}^{-}$est fortement influencée par le champ magnétique de fuite des aimants de l'extracteur. Ce champ magnétique divise la source en deux régions distinctes: une région sans champ magnétique, dans laquelle la densité d'ions $\mathrm{H}^{-}$est déterminée par la production en volume ; une deuxième région, proche de l'électrode plasma, où la concentration des ions $\mathrm{H}^{-}$est accrue par la diffusion des ions $\mathrm{H}^{-}$du plasma environnant, due aux pertes non compensées d'électrons sur l'électrode plasma polarisée positivement. Pour certaines valeurs de la polarisation de l'électrode plasma, l'augmentation de la densité d'ions $\mathrm{H}^{-}$près de cette électrode devient très grande, conduisant à des forts courants extraits.
\end{abstract}

\begin{abstract}
The density distribution of negative hydrogen ions along the axis of a hybrid multicusp $\mathrm{H}^{-}$ion source was measured, at different pressures, by using the photodetachement technique. It was found that in the region close to the plasma electrode (first electrode of the extractor) the negative ion density is strongly influenced by the stray magnetic field of the extractor magnets. This stray magnetic field divides the source into two distinct regions : a magnetic field-free region, in which the $\mathrm{H}^{-}$density is determined by volume production, and the region close to the plasma electrode, where the negative ion concentration is enhanced by diffusion from the surrounding plasma due to the unbalanced losses of electrons on the positively biased plasma electrode. For certain values of the bias potential the increase of $\mathrm{H}^{-}$density next to the plasma electrode is very large, leading to high extracted $\mathrm{H}^{-}$currents.
\end{abstract}

\section{Introduction.}

There is considerable interest in the development of intense volume negative ion sources for use in highenergy neutral beam heating and diagnostic systems for nuclear fusion plasmas. The initial work on volume production of $\mathrm{H}^{-}$ions in hydrogen plasmas $[1,2]$ has suggested that the dominant production mechanism is through dissociative attachment of low energy electrons $(\leqslant 1 \mathrm{eV})$ to highly vibrationally excited molecules [3].

In 1983 Leung et al. [4] reported the extraction of $\mathrm{H}^{-}$ions from the tandem or magnetically filtered multicusp plasma generator, developed earlier at the Lawrence Berkeley Laboratory for improving the proton ratio of positive ion sources [5]. In these sources, a magnetic filter separates the source into two parts : the source chamber, where the filaments are located, and the extraction chamber, wherefrom the ions are extracted. The magnetic filter is an array of permanent magnets, which provides a limited region of transverse magnetic field and prevents all energetic primary electrons in the source chamber from crossing into the extraction chamber, where a cold plasma is observed. It was then shown that :

(a) the addition of a magnetic filter to a conventional magnetic multicusp source not only enhances the extracted $\mathrm{H}^{-}$current, but sizeably reduces the extracted electron current ;

(b) the extracted negative ion current can be optimized and the electron current reduced, by biasing a few volts positive the first electrode of the extractor, which is in contact with the plasma (denoted as plasma electrode, PE). However, in the absence of the magnetic filter, no such effect is observed.

The plasma electrode bias seemed to flatten out the plasma potential gradients in the source, thus 
allowing the negative ions from the source to flow into the extractor $[4,6]$.

Holmes et al. [7] reported the design of the tandem source, developed at the Culham Laboratory. The transverse magnetic field is produced by an antisymmetric magnet pattern outside the source. In this source the positive plasma electrode bias reduced the extracted electron current, but did not optimize the extracted negative ion current.

Bacal et al. [8] found that one could optimize the extracted negative ion current not only in the tandem source, but also in a conventional and in a hybrid [9] multicusp plasma generator, and even in a plasma generator with no magnetic confinement (diffusion type). This occurred when the plasma electrode area was reduced to about $1 / 8$ of the total cross section area of the source. It appeared that the optimization of the extracted $\mathrm{H}^{-}$current was related to the optimization of the negative ion density in the extraction region, but not in the centre of the plasma [8].

In the present paper we show that in the hybrid multicusp source the observed increase in the extracted negative ion current and the reduction of the electron current, when the PE is biased positive, are due to the presence of a weak stray magnetic field in the plasma in front of the extractor, generated by the permanent magnets of the latter. We show that the value of the stray magnetic field is crucial for the extracted currents : the extracted $\mathrm{H}^{-}$ion current is the largest and the extracted electron component is the lowest when the stray magnetic field is strong enough.

The effect of the stray magnetic field upon the axial variation of the negative ion and electron densities along the source axis is reported. We show that, in presence of this stray magnetic field, the negative ion density in front of the extractor is optimized by the positive PE bias, while the electron density is reduced. We propose a mechanism to explain these phenomena and provide an interpretation for the variation of the extracted currents with this bias.

\section{Experimental set-up.}

In these experiments we investigate the hybrid multicusp ion source [9-11]. The stainless steel chamber is surrounded by ten samarium-cobalt magnets (with a surface magnetic field of $3500 \mathrm{G}$ ), with the north and south poles alternatively facing the plasma (Fig. 1). The end plates are not magnetized. The primary electrons are produced by ten thoriated tungsten filaments biased $50 \mathrm{~V}$ negative with respect to the chamber walls. These filaments are located in the upper part of the chamber, in the multicusp magnetic field (see Fig. 1b) ; each filament is placed
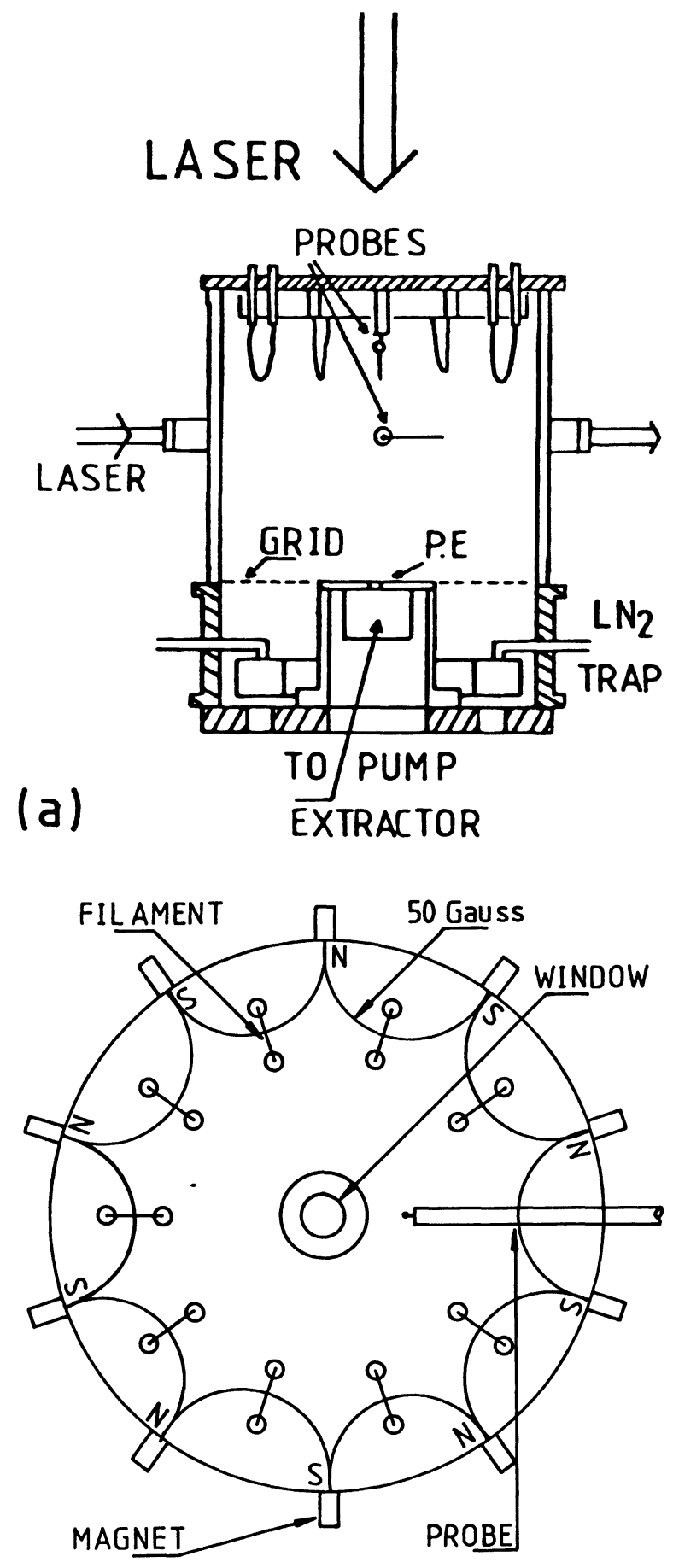

(b)

Fig. 1. - Cross sections through the hybrid multicusp - $\mathrm{H}^{-}$ion source.

in the radial plane passing through the saddle point of the multicusp magnetic field (in between two wall magnets). Due to the described above choice of the filament location, the primary electrons are trapped and confined in the neighbourhood of the cylindrical sidewall. Few energetic electrons espace into the central, magnetic field-free region, where, therefore, a low electron temperature plasma, favorable for volume $\mathrm{H}^{-}$production, is created [8]. 
Unless otherwise specified, all the measurements were made in a $50 \mathrm{~V}-5 \mathrm{~A}-2$ mtorr discharge. Note that the optimum pressure for negative ion formation in this source is 3 mtorr.

When investigating the extraction of volume produced $\mathrm{H}^{-}$ions from the hybrid multicusp source, we are interested in separating the electrons from the negative ions and in measuring separately their currents. We' use an extraction system consisting essentially of three electrodes [11]. The first electrode, in contact with the plasma (the plasma electrode, PE) has a circular extraction aperture, $0.8 \mathrm{~cm}$ in diameter. The second electrode, called "separator ", is located at $0.62 \mathrm{~cm}$ from PE and has also an opening $0.8 \mathrm{~cm}$ in diameter. A pair of Sm-Co magnets located in the separator, just behind the opening, creates a transverse magnetic field $(\geqslant 170 \mathrm{G}$ ) strong enough to deflect the accelerated electrons onto the separator, when the extraction voltage does not exceed $5 \mathrm{kV}$. The $\mathrm{H}^{-}$ions are weakly affected by the presence of this field, which causes only a small lateral displacement of the $\mathrm{H}^{-}$ion flux reaching the collector. The separator is made of soft iron, in order to minimize the stray magnetic fields. In some experiments this stray magnetic field was further reduced by shielding the back ends of the magnets with soft iron plates, or by replacing the Sm-Co magnets with weaker, ceramic magnets. We will show that the value of the stray magnetic field affects the extracted negative ion and electron currents.

The measurement of the stray magnetic field on the source axis, in front of PE, was made with a Hall probe and showed that the largest magnetic field component is parallel to PE (B-parallel). Figure 2 presents the dependence of the B-parallel value on the distance from $\mathrm{PE}$ for the two investigated situations :

a) without additional shielding of the Sm-Co extractor magnets («B-normal»), and

b) with soft iron plates added to the back ends of the Sm-Co magnets («B-reduced»). It can be seen that the magnetic screening reduces the maximum magnetic induction in front of PE from $20 \mathrm{G}$ to about $6 \mathrm{G}$.

The $\mathrm{H}^{-}$ion density was measured using the photodetachement technique $[12,13]$. In this technique the electron is detached from the $\mathrm{H}^{-}$ion by means of a pulsed laser beam and collected by a cylindrical tungsten probe $(0.5 \mathrm{~mm}$ in diam, $1.5 \mathrm{~cm}$ long) biased at $+20 \mathrm{~V}$ relative to the anode. This creates a probe current pulse, $\Delta i^{-}$, whose height is proportional to the $\mathrm{H}^{-}$ion density. The dc current to the probe, $i_{\mathrm{dc}}^{-}$, is proportional to the electron density. Therefore the measured ratio $\Delta i^{-} / i_{\mathrm{dc}}^{-}$gives the relative negative ion density $n_{-} / n_{\mathrm{e}}$. An independent measurement of $n_{\mathrm{e}}$ is necessary to determine

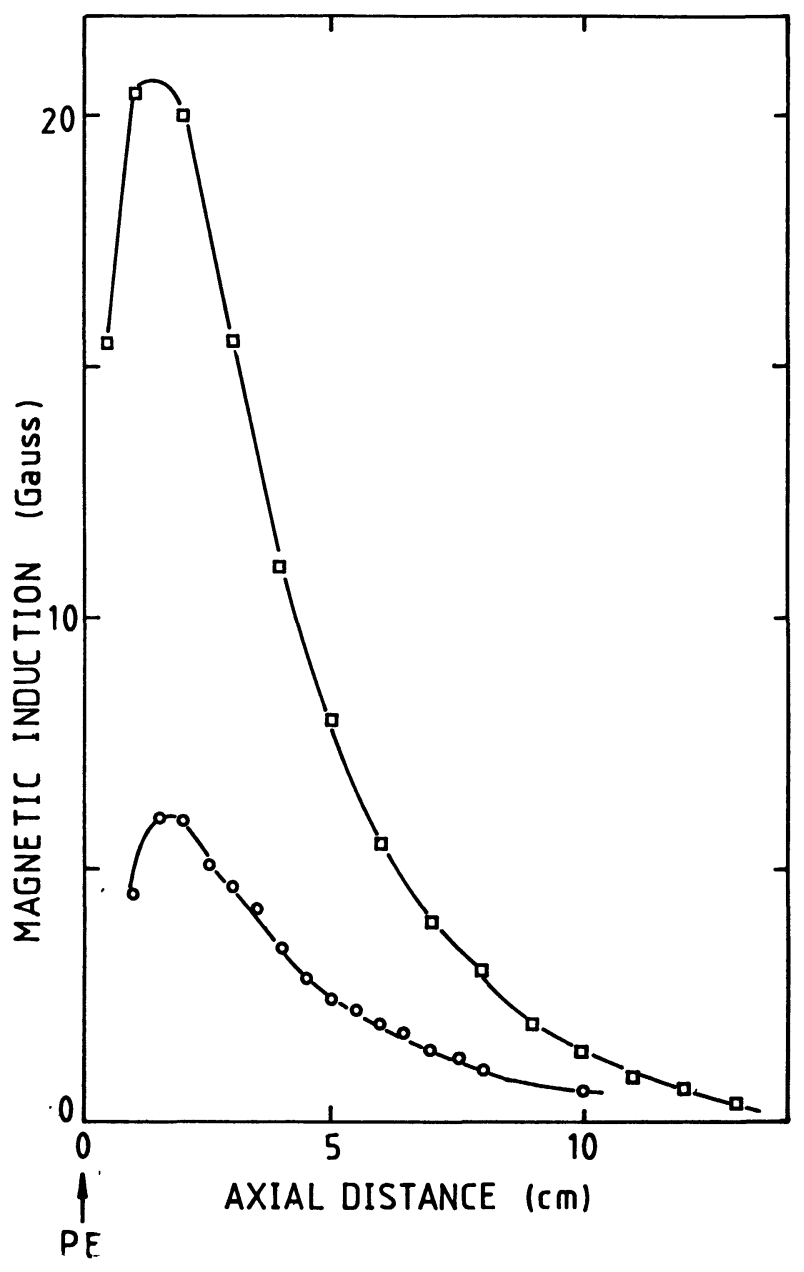

Fig. 2. - Component of the stray magnetic field parallel to $\mathrm{PE}$ versus distance to PE. Squares : B-normal ; circles : B-reduced.

$n_{-}$. We used a disk probe, $4 \mathrm{~mm}$ in diam. The laser beam was provided by a Nd:YAG laser $(380 \mathrm{~mJ} /$ pulse, $15 \mathrm{~ns}$ pulse duration), with a photon energy of $1.2 \mathrm{eV}$. The laser beam enters the plasma through a circular window in the upper flange and crosses the source along its axis. The cylindrical photodetachement probe is coaxial with the laser beam and can be moved along the source axis. In this way, it is possible to obtain an axial profile of the $\mathrm{H}^{-}$ion density.

\section{Axial variation of the plasma parameters.}

Figure 3 presents the variation of the electron density versus the axial distance from $\mathrm{PE}$, for B-reduced (Fig. 3a) and B-normal (Fig. 3b). The parameter is the positive PE bias potential, $V_{\mathrm{b}}$. An important observation concerning the effect of $V_{\mathrm{b}}$ follows from the examination of figure 3 : with B-reduced, the electron density goes down in the whole plasma (Fig. 3a), while with B-normal, the electron density is only reduced in the magnetized region close to PE (Fig. 3b), but attains much lower values, than with B-reduced. 


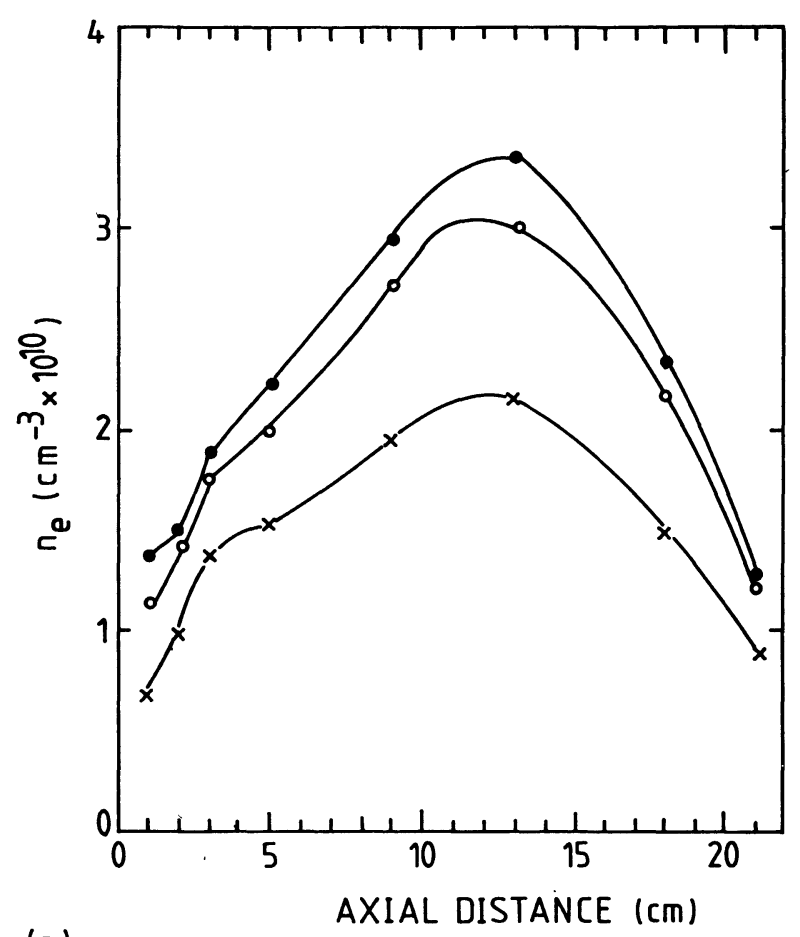

(a)

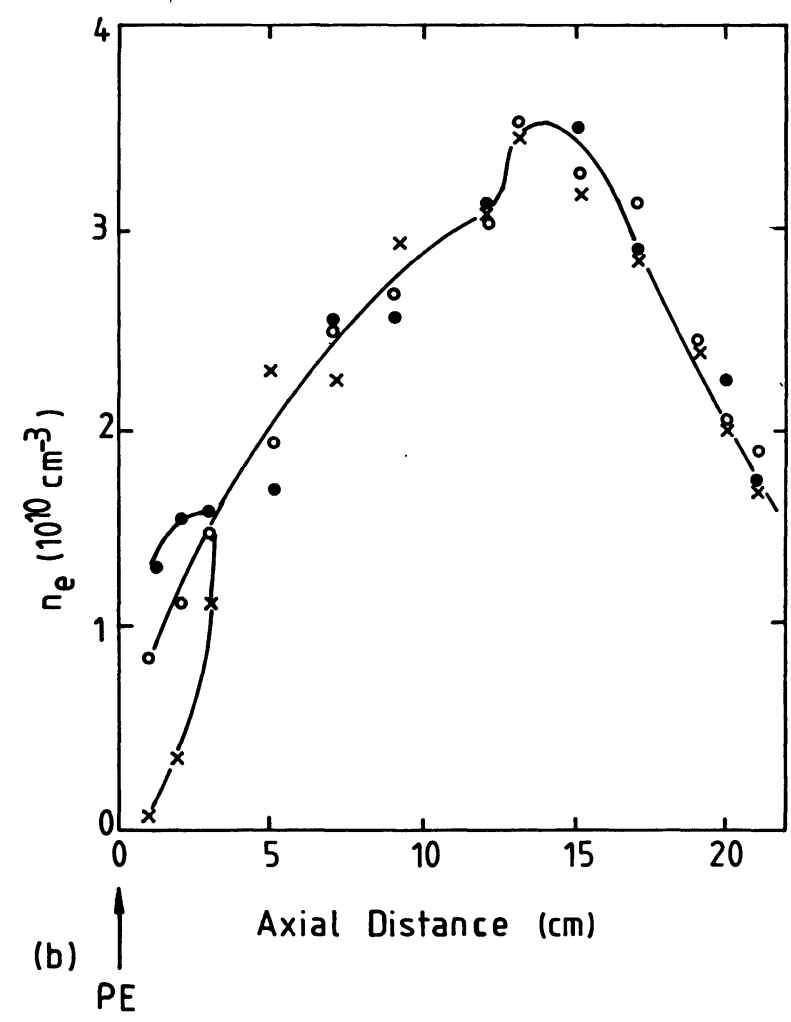

Fig. 3. - Electron density versus axial distance from the plasma electrode for a $50 \mathrm{~V}-5 \mathrm{~A}-2$ mtorr discharge, and for different values of $V_{\mathrm{b}} \cdot \bullet: V_{\mathrm{b}}=0 ; 0: V_{\mathrm{b}}=+1 \mathrm{~V}$; $x:+3$ V. a) B-reduced ; b) B-normal.

The role of the stray magnetic field, which can be idealized as parallel to $\mathrm{PE}$, is to magnetically insulate $P E$ from the plasma. It is shown in reference [14] that in a collisionless situation, with B-normal, the electrons present in the main plasma $(E \leqslant 50 \mathrm{eV})$ are unable to cross the transverse magnetic field and to attain PE. With B-reduced, electrons with $E \geqslant 15 \mathrm{eV}$ can reach PE. Therefore in the case Breduced, PE collects a large electron current and depletes the electron population in the whole plasma volume. With B-normal, the presence of electrons in the magnetized region could be due to diffusion across the magnetic field [15] and/or to secondary electron emission from $\mathrm{PE}$ surface at the location where B-field lines cross PE. When PE is biased positive it can deplete the electron population in the magnetized region, since the electron flow to $\mathrm{PE}$ is larger than the electron inflow in the magnetized region. The bulk of unmagnetized plasma is however unaffected.

Measurements made at different pressures in the range 2-8 mtorr yielded electron density profiles similar to those shown in figure 3 .

Figure 4 shows the axial variation of the electron temperature, $T_{\mathrm{e}}$, for both B-reduced and B-normal, when $P E$ is at the same potential as the chamber walls $\left(V_{b}=0\right)$. The electron temperature with $B$ normal is lower compared to the average value with B-reduced $(0.5 \mathrm{eV}$ compared to $0.8 \mathrm{eV})$. Note the weak, but smooth, axial variation of the electron temperature in the case B-reduced, while with Bnormal, $T_{\mathrm{e}}$ is constant along the whole source, but falls abruptly in the magnetized region near PE.

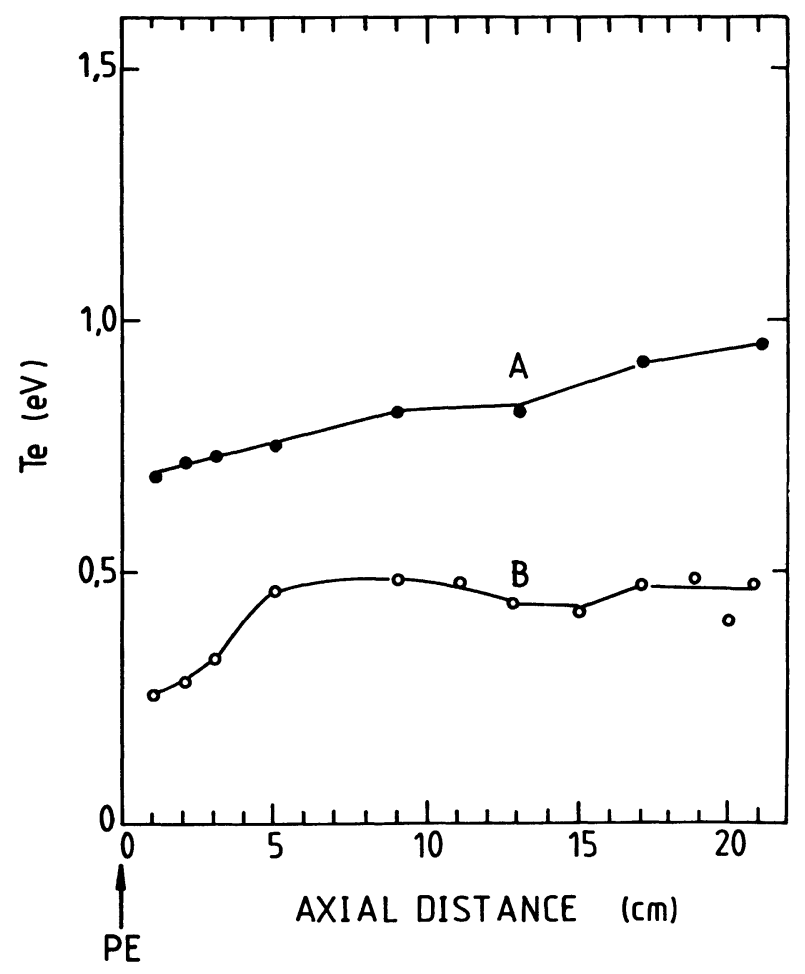

Fig. 4. - Electron temperature versus axial distance from $\mathrm{PE}$ for a $50 \mathrm{~V}-5 \mathrm{~A}-2$ mtorr discharge, with $V_{\mathrm{b}}=0$. Curve A : B-reduced ; curve B : B-normal. 
Biasing PE positive leads to an increase of the electron temperature in the whole plasma volume in the case B-reduced. With B-normal, $T_{\mathrm{e}}$ notably increases only in the magnetized region near PE.

Another notable difference is the behaviour of $T_{\mathrm{c}}$ with pressure. With B-reduced the electron temperature goes down when the pressure is increased : at 2 mtorr $T_{\mathrm{e}}$ is close to $1 \mathrm{eV}$, but decreases to $0.5 \mathrm{eV}$ when the pressure is increased to $8 \mathrm{mtorr}$. With B-normal, there is essentially no variation of
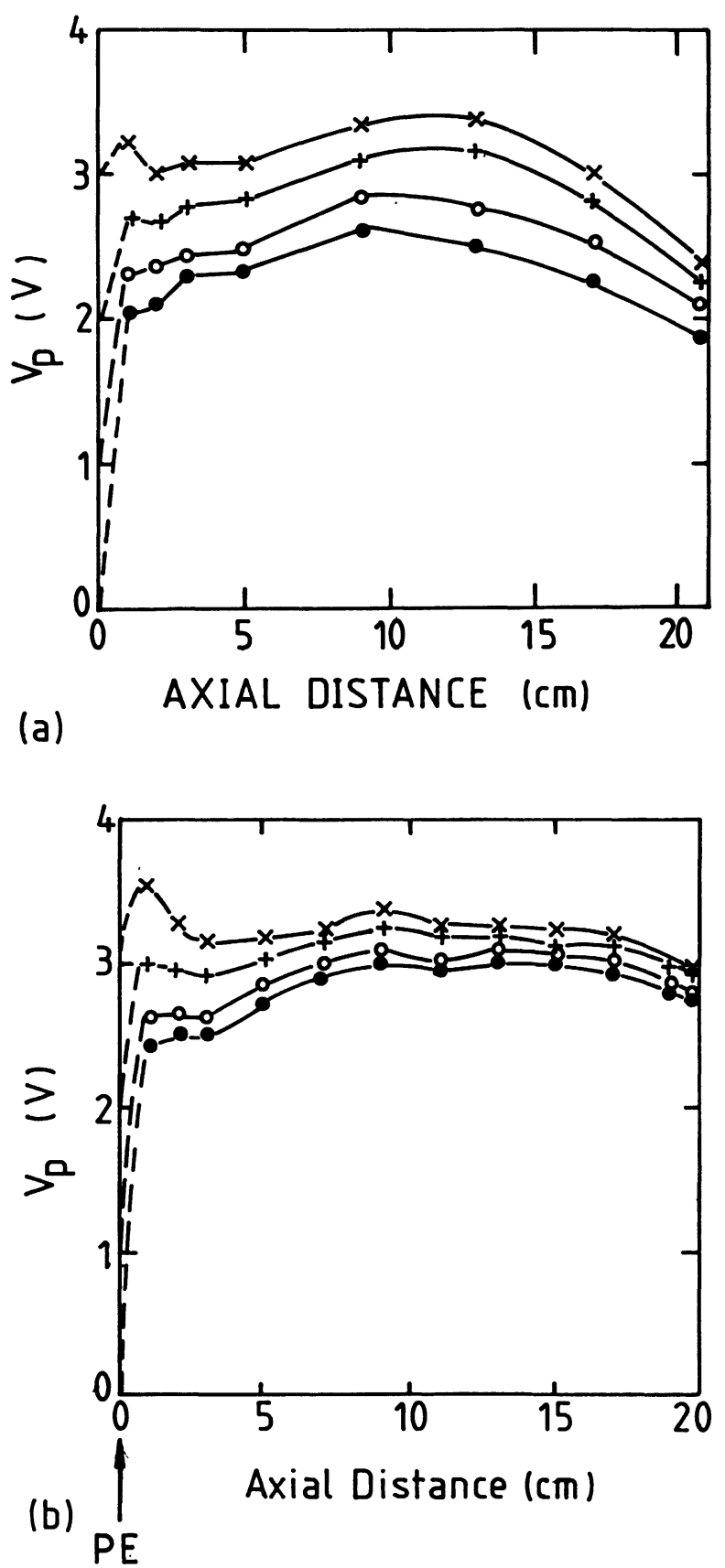

Fig. 5. - Variation of the plasma potential versus axial distance from $\mathrm{PE}$ for a $50 \mathrm{~V}-5 \mathrm{~A}-2$ mtorr discharge for different values of $V_{\mathrm{b}} \cdot \bullet: V_{\mathrm{b}}=0 ; 0: V_{\mathrm{b}}=+1 \mathrm{~V}$; $+: V_{\mathrm{b}}=+2 \mathrm{~V}$; $\times: x_{\mathrm{b}}=+3 \mathrm{~V}$. a) B-reduced; b) Bnormal.
$T_{\mathrm{c}}$ with pressure in the unmagnetized bulk of the plasma.

Figure 5 presents the variation of the plasma potential versus the axial distance from $\mathrm{PE}$, with $V_{\mathrm{b}}$ as a parameter. Note that with B-reduced the plasma potential is higher than with B-normal. In both magnetic field configurations, at $V_{\mathrm{b}}=0$, the plasma potential is maximum in the centre of the source, at the same location where the electron density is maximum, and decreases towards the end plates. The potential difference between the centre of the plasma and its axial boundaries is $0.5 \mathrm{~V}$ for $V_{\mathrm{b}}=0$. In a plasma with such a potential profile the negative ions and electrons are confined at the centre of the source and the positive ions are accelerated towards the walls.

When PE is biased positive, the plasma potential goes up in the whole source, in the case B-reduced, while with B-normal, the plasma potential increases essentially in the region close to PE. Note that with B-normal and $V_{\mathrm{b}}=+3 \mathrm{~V}$, the plasma potential near PE is higher than in the centre of the plasma, so that it repels the positive ions. With B-reduced, the plasma potential is maximum in the centre of the plasma in the range $V_{\mathrm{b}}=0_{\perp}+3 \mathrm{~V}$.

The effect of the PE bias, $V_{\mathrm{b}}$, upon the $\mathrm{H}^{-}$density profile is shown in figure 6 . In the case B-reduced (Fig. 6a) the $\mathrm{H}^{-}$density in the whole source attains a maximum when $V_{\mathrm{b}}$ is increased, and then goes down. The optimum $V_{\mathrm{b}}$ value for $n_{-}$is the same in the whole source. Note that under the same conditions the electron density decreases continuously with increasing $V_{\mathrm{b}}$ (Fig. 3). As mentioned in section 1 , it is assumed $[1,2]$ that the $\mathrm{H}^{-}$formation process is through dissociative attachement of electrons to highly rovibrationally excited $\mathrm{H}_{2}$. In meantime we did not find a significant change in electron temperature. Therefore we conclude that the reduction of the electron density which diminishes the $\mathrm{H}^{-}$production, is compensated by a decrease of the $\mathrm{H}^{-}$destruction rates.

With B-normal, the effect of $V_{\mathrm{b}}$ on $n_{-}$is limited to the magnetized region near $\mathrm{PE}$; here the $\mathrm{H}^{-}$density attains values which are larger than in the bulk of the plasma, where this density is almost unaffected by $V_{\mathrm{b}}$. Note that values $\left(n_{-} / n_{\mathrm{e}}\right)>1$ are observed in the magnetized region. The $\mathrm{H}^{-}$density increases with $V_{\mathrm{b}}$ until a maximum value is attained. Note that the optimum $V_{\mathrm{b}}$ value depends on pressure : it goes down when the pressure goes up.

The new important fact indicated by figure 6 is that the negative ion density increases in the region where the electron density is reduced. This suggests that the negative ions arrive from the main plasma into the magnetized region close to $\mathrm{PE}$, where the plasma neutrality is perturbed by the action of the magnetic field, which blocks the electrons. As a matter of fact, the heavier (compared to the elec- 


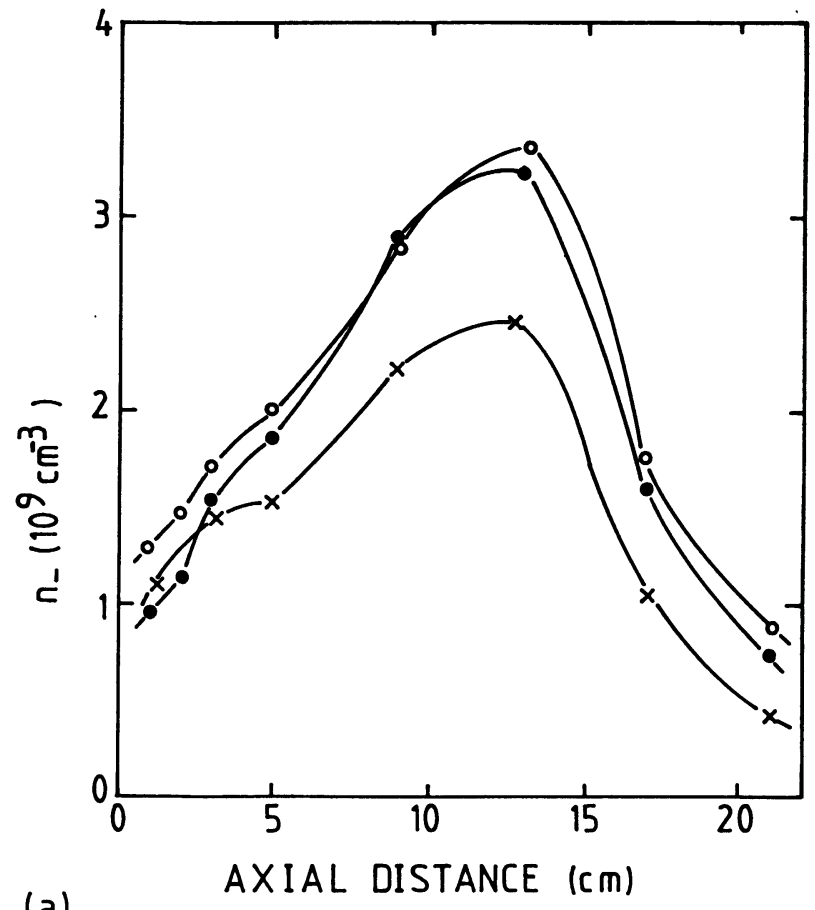

(a)

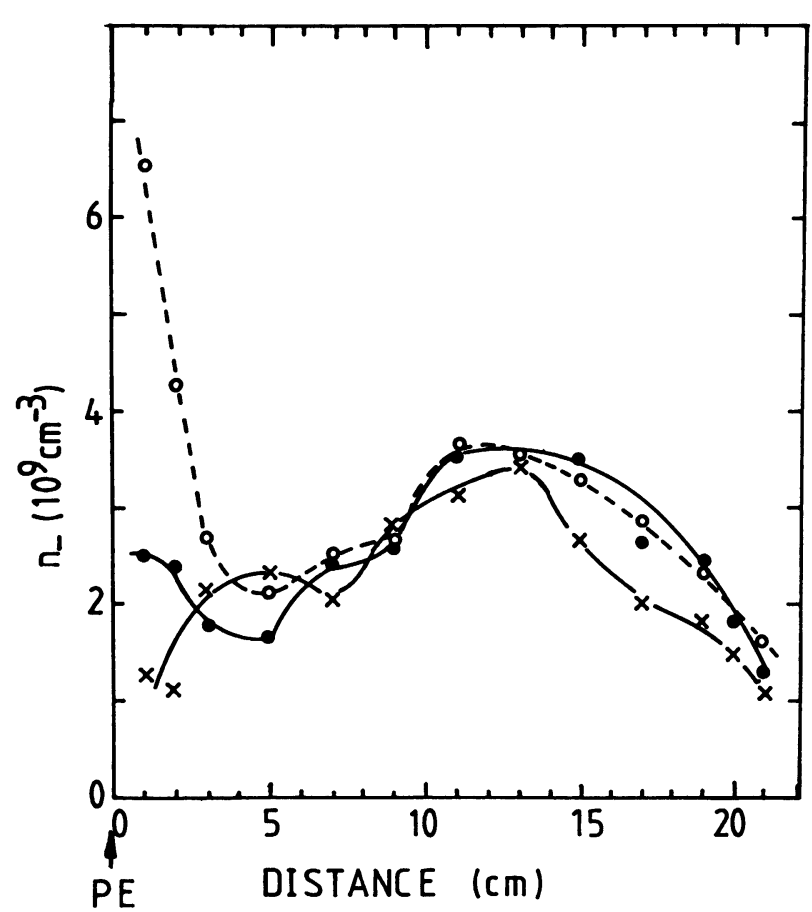

(b)

Fig. 6. $-\mathrm{H}^{-}$density versus axial distance from $\mathrm{PE}$ for different values of $\mathrm{V}_{\mathrm{b}}$. $50 \mathrm{~V}-5 \mathrm{~A}-2 \mathrm{mtorr}$ discharge. - : $V_{\mathrm{b}}=0 ; 0:+1 \mathrm{~V} ; \times: V_{\mathrm{b}}=+3 \mathrm{~V}$. a) B-reduced ; b) B-normal.

trons) positive ions are unaffected by the weak magnetic field employed, but their flow to PE is affected by two factors :

1. The electron motion is controlled by the magnetic field; this modifies the ambipolar flow in the neighbourhood of PE.
2. The PE potential, which modifies the plasma potential gradient in the plasma near PE; the positive PE would even repel the positive ions when $V_{\mathrm{b}} \geqslant V_{\mathrm{P}}$

Figure 7 shows that the dependence of the extracted negative ion current, $I^{-}$, and electron cur-
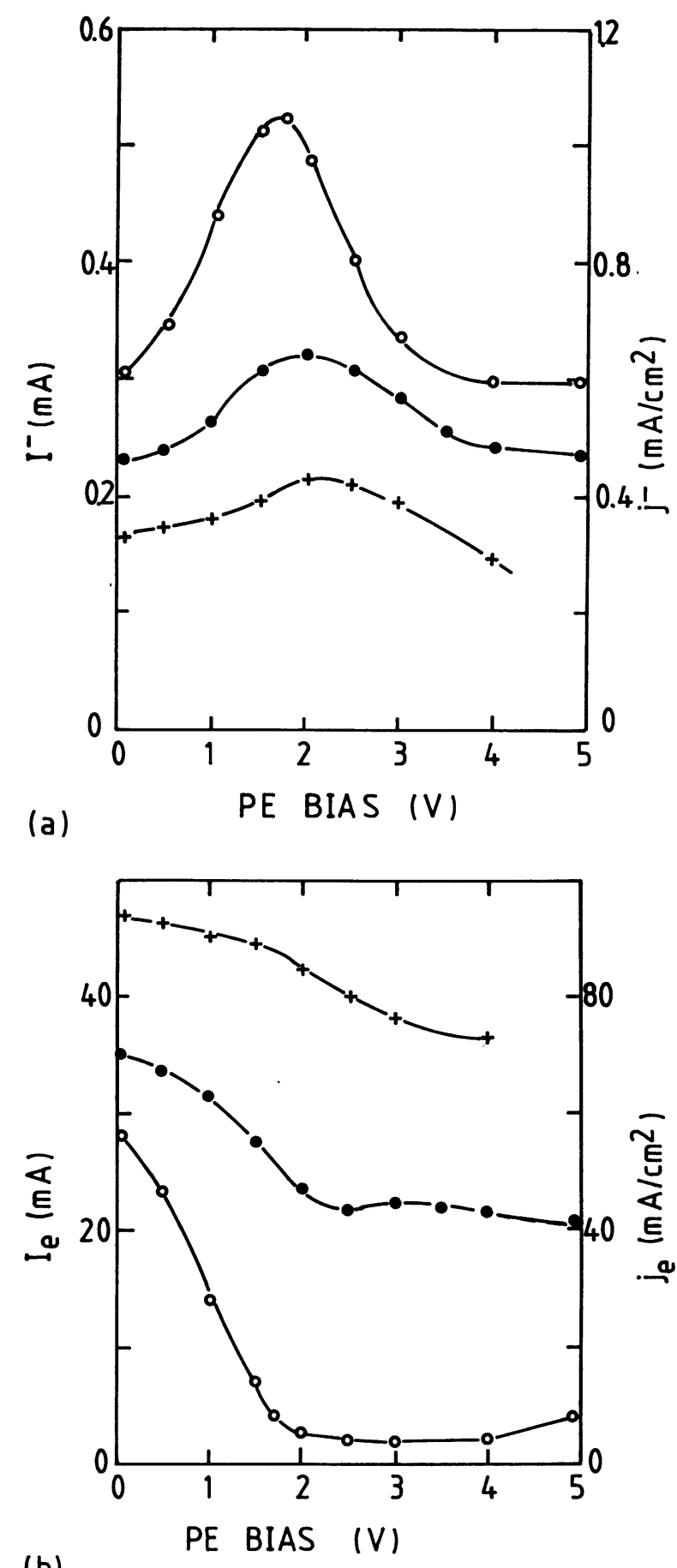

(b)

Fig. 7. - Dependence of the extracted negative ion and electron currents upon PE bias, with different magnetic fields in front of PE. O : B-normal (largest B) ; $\bullet$ : ceramic magnets in the separator (medium B); + : B-reduced (lowest B). 50 V-10 A-2.5 mtorr discharge. Extraction voltage : $1 \mathrm{kV}$. 
rent, $I_{\mathrm{e}}$, on $V_{\mathrm{b}}$ is affected by the stray magnetic field value in front of $\mathrm{PE}$. $\mathrm{I}^{-}$exhibits the most pronounced maximum and attains the largest value, and $I_{\mathrm{e}}$ exhibits the largest reduction, when the stray magnetic field in the plasma is the strongest.

It can be noted that the variation of the extracted $\mathrm{H}^{-}$and electron currents versus $V_{\mathrm{b}}$ reflects the corresponding variation of $\mathrm{H}^{-}$and electron densities in the extraction region (Figs. 3 and 6).

\section{Conclusion.}

The important observation of this work is that the presence of a relatively weak magnetic field in front of PE (such as to magnetically insulate PE from the electrons in the unmagnetized bulk plasma, without affecting the ion flow) can produce important modifications in the electron and negative ion densities near PE, and, as a result, in the extracted currents. The ion flow is much less affected by the magnetic field and is not reduced, as long as the plasma potential is not modified so that the positive ions are still accelerated towards PE.

Under such conditions, an unbalance between the positive ion and electron fluxes across the magnetized region can occur; in order to ensure plasma neutrality near PE, more negative ions arrive in the magnetized region together with positive ions, to replace the missing electrons. Thus the $\mathrm{H}^{-}$density and the ratio $n_{-} / n_{\mathrm{e}}$ become very high, as observed at the optimum value of the PE bias.

For larger values of $V_{\mathrm{b}}$, the plasma potential in front of PE begins to repel the positive ions towards the main plasma volume. The flux of positive ions is reduced [9] and the flux of $\mathrm{H}^{-}$, approximately equal to the positive ion flux, goes down, too. This is the reason why, for $V_{\mathrm{b}} \geqslant V_{\mathrm{b}}$ opt the $\mathrm{H}^{-}$density in front of PE decreases.

The understanding of the joint action of both the positive bias of $\mathrm{PE}$ and the small transverse magnetic field in front of it is of importance for the design of ion sources and extraction systems, in which the negative ion current is maximized, while the electron current is reduced.

One could argue that there is a certain similarity between the experimental means used in the hybrid source, with the magnetic filter, used in tandem sources $[4,7]$. This similarity is only apparent. In the present experiments the magnetic field in front of PE acts only upon the extraction, by concentrating in the extraction region the negative ions formed in the main, unmagnetized, plasma. In the tandem configuration the role of the magnetic filter is to create the extraction plasma region, where the negative ions are produced [16].

Further work will be done to study the radial variation of the negative ion density, in order to determine the main characteristics of a multi-aperture extractor.

\section{Acknowledgments.}

This work was supported by Ecole Polytechnique and Centre National de la Recherche Scientifique (France).

\section{References}

[1] Bacal, M. and Hamilton, G. W., Phys. Rev. Lett., 42 (1979) 1538.

[2] Bacal, M., Bruneteau, A. M., Graham, W. G., Hamilton, G. W. and NaChman, M., J. Appl. Phys., 52 (1981) 1247.

[3] Wadehra, J. M. and Bardsley, J. N., Phys. Rev. Lett., 55 (1978) 15.

[4] Leung, K. N., Ehlers, K. W. and BACAL, M., Rev. Sci. Instrum., 54 (1983) 56.

[5] Ehlers, K. W. and Leung, K. N., Rev. Sci. Instrum., 52 (1981) 1452.

[6] LeUnG, K. N. and BACAL, M., Rev. Sci. Instrum., 55 (1984) 338.

[7] Holmes, A. J. T., Dammertz, G. and Green, T. S., Rev. Sci. Instrum., 56 (1985) 1697.

[8] BaCAl, M., Hillion, F. and NAChMan, M., Rev. Sci. Instrum., 56 (1985) 649.

[9] Bacal, M., Bruneteau, A. M. and Nachman, M., J. Appl. Phys., 55 (1984) 15.

[10] Bacal, M., Bruneteau, J., Devynck, P. and Hillion, F., Proc. 4th Symposium on the Production and Neutralization of Negative Ions and
Beams, Brookhaven National Laboratory, Upton, N.Y., October 1986, AIP Conference Series, to be published.

[11] Bacal, M., Bruneteau, J., Devynck, P. and Hillion, F., Production and Application of Light Negative Ions, Proceedings of the 2nd European Workshop, March 5-7, 1986, Ecole Polytechnique, Palaiseau, France (Edited by M. Bacal and Ch. Mouttet) p. 201.

[12] Bacal, M., Hamilton, G. W., Bruneteau, A. M., Doucet, H. J. and TAillet, J., Rev. Sci. Instrum., 50 (1979) 719.

[13] BACAL, M., Phys. Scr. 2/2 (1982) 467.

[14] Bruneteau, J., Production and Application of Light Negative Ions, Proceedings of the 2nd European Workshop, March 5-7, 1986, Ecole Polytechnique, Palaiseau, France (Edited By M. Bacal and Ch. Mouttet) p. 81.

[15] Holmes, A. J. T., Rev. Sci. Instrum., 53 (1982) 1517.

[16] Hiskes, J. R. and Karo, A. M., J. Appl. Phys. 56 (1984) 1927. 